\title{
Phosphorus-doped thin silica films characterized by magic-angle spinning nuclear magnetic resonance spectroscopy
}

\author{
Jacobsen, H.J.; Skibsted, J.; Kristensen, Martin; Zauner, Dan
}

Published in:

Journal of Applied Physics

Link to article, DOI:

$10.1063 / 1.1351545$

Publication date:

2001

Document Version

Publisher's PDF, also known as Version of record

Link back to DTU Orbit

Citation (APA):

Jacobsen, H. J., Skibsted, J., Kristensen, M., \& Zauner, D. (2001). Phosphorus-doped thin silica films characterized by magic-angle spinning nuclear magnetic resonance spectroscopy. Journal of Applied Physics, 89(7), 4134-4138. https://doi.org/10.1063/1.1351545

\section{General rights}

Copyright and moral rights for the publications made accessible in the public portal are retained by the authors and/or other copyright owners and it is a condition of accessing publications that users recognise and abide by the legal requirements associated with these rights.

- Users may download and print one copy of any publication from the public portal for the purpose of private study or research.

- You may not further distribute the material or use it for any profit-making activity or commercial gain

- You may freely distribute the URL identifying the publication in the public portal 


\title{
Phosphorus-doped thin silica films characterized by magic-angle spinning nuclear magnetic resonance spectroscopy
}

\author{
Hans J. Jakobsen and Jørgen Skibsted \\ Department of Chemistry, Instrument Centre for Solid-State NMR Spectroscopy, University of Aarhus, \\ DK-8000 Århus C, Denmark \\ Martin Kristensen ${ }^{\mathrm{a})}$ and Dan A. Zauner ${ }^{\mathrm{b})}$ \\ Research Center COM, DTU Building 345 West, DK-2800 Kgs. Lyngby, Denmark
}

(Received 6 September 2000; accepted for publication 22 December 2000)

\begin{abstract}
Magic-angle spinning nuclear magnetic resonance spectra of ${ }^{31} \mathrm{P}$ and ${ }^{29} \mathrm{Si}$ have been achieved for a thin silica film doped with only $1.8 \%{ }^{31} \mathrm{P}$ and deposited by plasma enhanced chemical vapor deposition on a pure silicon wafer. The observation of a symmetric ${ }^{31} \mathrm{P}$ chemical shift tensor is consistent with a three-fold symmetric $(-\mathrm{O}-)_{3} \mathrm{P}=\mathrm{O}$ chemical structure. We find that the glass structure is very similar to that found in fiber preforms. (C) 2001 American Institute of Physics.
\end{abstract}

[DOI: $10.1063 / 1.1351545]$

\section{INTRODUCTION}

Glass fibers and integrated optical components are essential parts of today's telecommunication networks. Production of high-quality glass components is of significant technological importance. Intensive research efforts are devoted to the development of new types of glasses with special properties such as low optical loss, special stress, high sensitivity to ultraviolet light, long-time stability, and amplification by doping with rare earth elements. Despite the technological importance and advances, a fundamental understanding of relationships between structure and physical properties of glass materials lags far behind that of crystalline materials. This is due to the significant complications involved in studies of amorphous material. Therefore, there is an urgent need to improve our knowledge on the structure/ property relationships by characterization of such complicated materials. X-ray diffraction is a well-established method for determination of the short-range order and longrange disorder in glasses. ${ }^{1,2}$ Additional information about the local environment may be obtained with more modern x-ray techniques such as extended $\mathrm{x}$-ray absorption fine structure spectroscopy, ${ }^{3}$ however, structural information beyond the first few atomic neighbors is difficult to obtain by these techniques. Various kinds of defects in glasses have been studied using electron paramagnetic resonance spectroscopy, ${ }^{4,5}$ and some information has been gained from optical spectroscopy. ${ }^{6-8}$ Despite these systematic spectroscopic investigations most knowledge about glass properties is still obtained through simple trial and error methods.

Nuclear magnetic resonance (NMR) spectroscopy is one of the few techniques that can provide improved structural information about amorphous inorganic materials such as

\footnotetext{
a) Author to whom correspondence should be addressed; electronic mail: mk@com.dtu.dk

${ }^{b)}$ Present address: Dan A. Zauner, SP DV 02 6, Corning Incorporated, Corning, New York 14831, USA.
}

glass. During the past 2 decades solid-state NMR spectroscopy has been developed to a level where it is possible to obtain valuable information and insight into the complicated structures of amorphous materials. For example, extensive NMR studies have been performed on bulk glass samples ${ }^{9,10}$ and fiber preforms. ${ }^{11,12}$ However, a general drawback of the NMR method is the need for a sufficient quantity of sample material. This makes the application of solid-state NMR to fibers and thin films very cumbersome. Thus, so far no investigations have been directed toward the structural characterization of a high-quality thin film glass by NMR because of the need for considerable quantities of material for the sensitivity of solid-state NMR to yield clear-cut information.

This article reports on the application of solid-state magic-angle spinning (MAS) NMR spectroscopy, employing proprietary high-sensitivity MAS probes, to characterize the structure at the molecular level of phosphorus-doped thin (34 $\mu \mathrm{m})$ silica films. ${ }^{31} \mathrm{P}$ and ${ }^{29} \mathrm{Si}$ MAS NMR spectra recorded at 7.1 and $9.4 \mathrm{~T}$ for specially prepared samples of the phosphorus-doped thin silica films have provided unique NMR parameters related to the structure at the molecular level.

\section{EXPERIMENTAL PROCEDURES}

\section{A. Preparation of samples}

We deposit thin glass films using plasma enhanced chemical vapor deposition (PECVD) on $350 \mu \mathrm{m}$ thick highpurity 4 in. diam [100] silicon substrates (wafers). As glass precursors we use $\mathrm{SiH}_{4}$ and $\mathrm{N}_{2} \mathrm{O}$ for pure silica films and $\mathrm{PH}_{3}$ for phosphorous doping. The deposition takes place at $300{ }^{\circ} \mathrm{C}$ with a surplus of $\mathrm{N}_{2} \mathrm{O}$ in order to reduce the hydrogen content in the film. After deposition the samples are annealed for $12 \mathrm{~h}$ in $\mathrm{N}_{2}$ at $1100^{\circ} \mathrm{C}$ in order to consolidate the glass and remove any remaining hydrogen. It is impossible to deposit sufficient glass thickness in one run to enable NMR spectroscopy of the material because of problems with stress and poor adhesion of thick unconsolidated layers. Therefore, 
three consecutive glass depositions were performed with anneal steep in-between and a total deposit of $36 \mu \mathrm{m}$ glass on the wafers. Two such wafers were fabricated with thin glass film. The glass on wafer No. 1 was doped with $3.5 \% \pm 0.5 \%$ $\mathrm{P}$ and on wafer No. 2 it was doped with $1.8 \% \pm 0.3 \% \mathrm{P}$. The $\mathrm{P}$ concentration (at. \%) was confirmed by measuring the refractive index at $632.8 \mathrm{~nm}$ using a prism coupler and comparing to standard tables which have been calibrated by $\mathrm{Ru}-$ therford back scattering and confirmed by $\mathrm{x}$-ray spectroscopy. The results agree well with those obtained by others. ${ }^{11}$ After deposition and annealing sufficient glass material for NMR spectroscopy was obtained. However, the total glass concentration for the intact wafer is too low, because the glass is diluted by a factor of 10 due to the silicon from the wafer. In order to increase the glass concentration most of the silicon wafer was removed by etching in 33\% w/w $\mathrm{KOH}$ at $45^{\circ} \mathrm{C}$ for about $2 \mathrm{~d}$. Because of the increased selectivity between silicon and glass etching at low temperature, only approximately $2 \mu \mathrm{m}$ of the glass was removed. In addition, low temperature reduces diffusion of $\mathrm{K}^{+}$ions into the glass. After etching the silicon wafer, the residual glass is left as small pieces (due to stress) which were carefully collected and cleaned with de-ionized water followed by a $1 \mathrm{~h}$ treatment with water at $95^{\circ} \mathrm{C}$ in order to extract $\mathrm{K}^{+}$ions that may have diffused into the glass. Afterwards the glass is dried and ready for NMR spectroscopy. Using the same type of glass for fabrication of integrated waveguides and measuring the transmission spectrum of a light emitting diode through $50 \mathrm{~mm}$ of waveguide with an optical spectrum analyzer (model ANDO AQ-6321B) we find that the hydrogen concentration is below the detection level for $\mathrm{OH}$ near 1400 nm. ${ }^{13}$

\section{B. NMR spectroscopy}

${ }^{31} \mathrm{P},{ }^{29} \mathrm{Si}$, and ${ }^{1} \mathrm{H}$ MAS NMR experiments were performed at 161.9, 79.5, and $399.9 \mathrm{MHz}$, respectively, on a Varian Unity INOVA-400 spectrometer $(9.4 \mathrm{~T})$ while some of the preliminary ${ }^{31} \mathrm{P}$ and ${ }^{29} \mathrm{Si}$ experiments were also carried out at 121.4 and $59.6 \mathrm{MHz}$ on a Unity INOVA-300 spectrometer $(7.1 \mathrm{~T})$. Home-built multinuclear MAS probes ${ }^{14}$ for 7 and $4 \mathrm{~mm}$ rotors with exact magic-angle setting were employed. To increase the sensitivity of the experiments a specially designed thin-wall $7 \mathrm{~mm}$ outer diameter $\mathrm{Si}_{3} \mathrm{~N}_{4}$ rotor with an inner diameter of $6.0 \mathrm{~mm}$ was used. This rotor has a sample volume of $325 \mu \mathrm{l}$, compared to the volume of $225 \mu \mathrm{l}$ for the standard $7 \mathrm{~mm}$ rotor of $1 \mathrm{~mm}$ wall thickness, and gives an increase in sensitivity by approximately $40 \%-50 \%$. The ${ }^{31} \mathrm{P}$ MAS experiments employed rotor speeds in the range from 3500 to $7000 \mathrm{~Hz}$ with both speeds being automatically controlled to within $\pm 1 \mathrm{~Hz}$, a spectral width of 100 $\mathrm{kHz}$, single-pulse excitation with a pulse width $\tau_{p}=5.6 \mu \mathrm{s}$ (corresponding to a $\pi / 2$ flip angle, $\gamma B_{1} / 2 \pi=45 \mathrm{kHz}$ ), and relaxation delays varying from 4 to $3000 \mathrm{~s}$. The ${ }^{29} \mathrm{Si}$ MAS experiments used a spectral width of $50 \mathrm{kHz}$, single pulse excitation with a pulse width $\tau_{p}=4 \mu$ s (corresponding to a $\pi / 3$ flip angle, $\gamma B_{1} / 2 \pi=36 \mathrm{kHz}$ ), and relaxation delays from 40 to $180 \mathrm{~s}$. Isotropic chemical shifts are in ppm relative to external $85 \% \mathrm{H}_{3} \mathrm{PO}_{4}$ for ${ }^{31} \mathrm{P}$ and neat tetramethylsilane for
${ }^{29} \mathrm{Si}$. Simulations and fittings of experimental spectra were performed on a SUN Sparc 10/51 workstation of the Unity INOVA-400 spectrometer using the solid-state NMR software package STARS (SpecTrum Analysis of Rotating Solids) developed in our laboratory. ${ }^{15}$ The chemical shift anisotropy (CSA) is defined by the parameters

$$
\begin{aligned}
& \delta_{\text {iso }}=1 / 3\left(\delta_{x x}+\delta_{y y}+\delta_{z z}\right) \\
& \delta_{\sigma}=\delta_{\text {iso }}-\delta_{z z} \quad \eta_{\sigma}=\left(\delta_{x x}-\delta_{y y}\right) / \delta_{\sigma},
\end{aligned}
$$

where the principal elements of the chemical shift tensor $\delta_{x x}, \quad \delta_{y y}$, and $\delta_{z z}$ are defined as $\left|\delta_{z z}-\delta_{\text {iso }}\right| \geqslant\left|\delta_{x x}-\delta_{\text {iso }}\right|$ $\geqslant\left|\delta_{y y}-\delta_{\text {iso }}\right|$.

\section{RESULTS AND DISCUSSION}

${ }^{1} \mathrm{H}$ MAS NMR experiments using a $4 \mathrm{~mm}$ rotor and $v_{r}$ $=15 \mathrm{kHz}$ were performed for glass No. 1 in order to test for the presumed low hydrogen content in the glass. Difference spectroscopy between the ${ }^{1} \mathrm{H}$ MAS spectra for a filled and empty rotor indeed shows that the hydrogen concentration for the glass is below the detection level for ${ }^{1} \mathrm{H}$ NMR. This precludes the application of ${ }^{1} \mathrm{H}$ cross polarization $(\mathrm{CP})$ for the ${ }^{31} \mathrm{P}$ and ${ }^{29} \mathrm{Si}$ MAS NMR experiments.

For the ${ }^{31} \mathrm{P}$ NMR investigation an array of relaxation delays from 4 to $3000 \mathrm{~s}$ for the single-pulse MAS experiments shows that the ${ }^{31} \mathrm{P}$ spin-lattice relaxation time $T_{1}$ for the phosphorus dopant is on the order of $1000 \mathrm{~s}$. Thus, employing $\pi / 2$ pulse excitation and a relaxation delay of $2000 \mathrm{~s}$ we obtain ${ }^{31} \mathrm{P}$ MAS NMR spectra with appropriate signal-to-noise ratios for spectral simulations in 32 scans, i.e., during an overnight run. Figure 1 illustrates two ${ }^{31} \mathrm{P}$ MAS NMR spectra of glass No. 1 recorded at $7.1 \mathrm{~T}$ for two different sample spinning speeds: 3760 and $6845 \mathrm{~Hz}$. Both spectra exhibit a manifold of spinning sidebands of varying intensity, which are typical for a CSA powder pattern of a spin- $1 / 2$ nucleus undergoing sample rotation. The linewidths for the individual sidebands are quite broad, typical for an amorphous material, and about $1400 \mathrm{~Hz}$ wide at half height. From the spectrum in Fig. 1(c) it appears that for spinning speeds slower than $\sim 3500 \mathrm{~Hz}$, the sidebands will start merging. Comparison of the spectra for the two spinning speeds in Fig. 1 immediately identifies the resonance at $-38 \mathrm{ppm}$ as the isotropic peak. Iterative computer fitting of the line shapes for the two manifolds of spinning sidebands in Figs. 1(a) and 1(c) shows that only a single well-defined tetrahedral P site is required for a perfect fit. Two almost identical parameter sets (Table I) are determined from the ${ }^{31} \mathrm{P}$ MAS NMR spectra obtained at $7.1 \mathrm{~T}$ (Fig. 1). The recording of ${ }^{31} \mathrm{P}$ MAS NMR spectra for glass No. 2 employed the $9.4 \mathrm{~T}$ spectrometer in order to enhance sensitivity because of the lower phosphorus content for the glass on this wafer $(1.8 \% \mathrm{P}) .{ }^{31} \mathrm{P}$ MAS NMR spectra obtained at $9.4 \mathrm{~T}$ and for two different spinning frequencies $(4000$ and $6000 \mathrm{~Hz}$ ) are shown in Fig. 2 along with simulations corresponding to the optimized parameters (Table I) resulting from the spectral analysis. These data are very similar to those for glass No. 1 indicating identical phosphorus molecular entities for the two different $\mathrm{P}$ concentrations in the silica glass. All parameters (average values: $\delta_{\text {iso }}=-38.3 \pm 1.0 \mathrm{ppm}, \delta_{\sigma}=+148 \pm 3 \mathrm{ppm}$, and $\eta_{\sigma}$ 

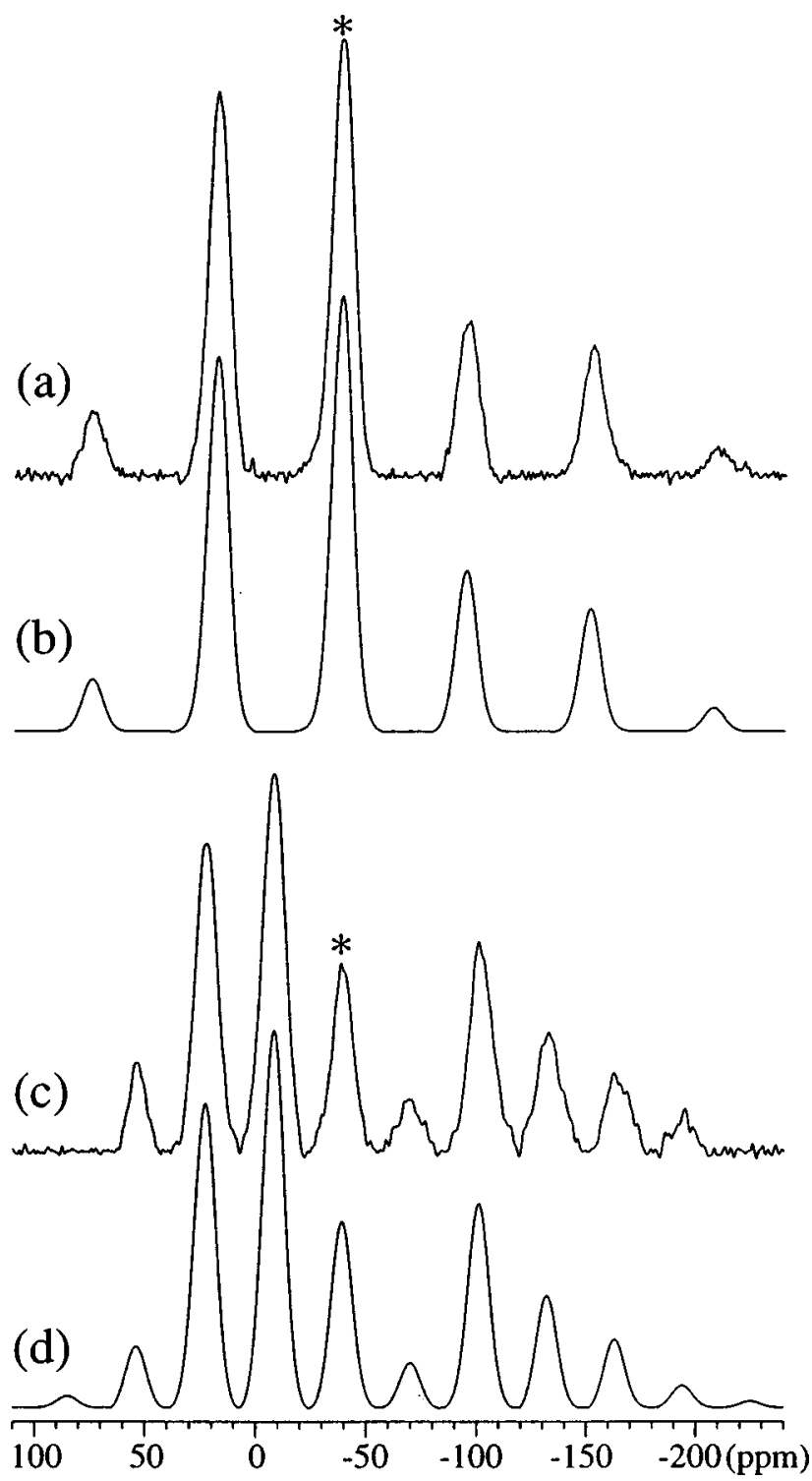

FIG. 1. Experimental ${ }^{31} \mathrm{P}$ MAS NMR spectra $(7.1 \mathrm{~T})$ of glass No. $1(3.5 \% \mathrm{P}$ conc.) recorded using: (a) $v_{r}=6845 \mathrm{~Hz}$ and (c) $v_{r}=3760 \mathrm{~Hz}$. The asterisks indicate the resonances corresponding to the isotropic chemical shift. The optimized simulations of the manifolds of spinning sidebands in (a) and (c) are shown in (b) and (d), respectively, and correspond to the ${ }^{31} \mathrm{P}$ CSA parameters listed in Table I.

$=0.12 \pm 0.13)$ indicate an axially symmetric ${ }^{31} \mathrm{P}$ shift tensor and thereby a threefold symmetry axis for the $\mathrm{PO}_{4}$ tetrahedron. This is consistent with a $(-\mathrm{O}-)_{3} \mathrm{P}=\mathrm{O}$ phosphorus tetrahedron where the three oxygen are covalently bonded to three $\mathrm{Si}$ atoms of the silica glass as sketched in Fig. 3.

We note that the ${ }^{31} \mathrm{P}$ CSA parameters determined for our $34 \mu \mathrm{m}$ phosphorus-doped thin silica film are quite similar to the data obtained from static powder ${ }^{31} \mathrm{P}$ NMR for a glass fiber preform core ${ }^{11}$ prepared as a phosphorus-doped silica glass by modified chemical vapor deposition. The principal components of the ${ }^{31} \mathrm{P}$ shift tensor determined from the static ${ }^{31} \mathrm{P}$ NMR spectrum of a $1.12 \%$ phosphorus glass in such a preform were: $\delta_{x x}=\delta_{y y}=37 \mathrm{ppm}$ and $\delta_{z z}=-190 \mathrm{ppm}^{11}$ (note: the data originally reported on the shielding $\sigma$ scale has been converted to today's more commonly used $\delta$ scale).

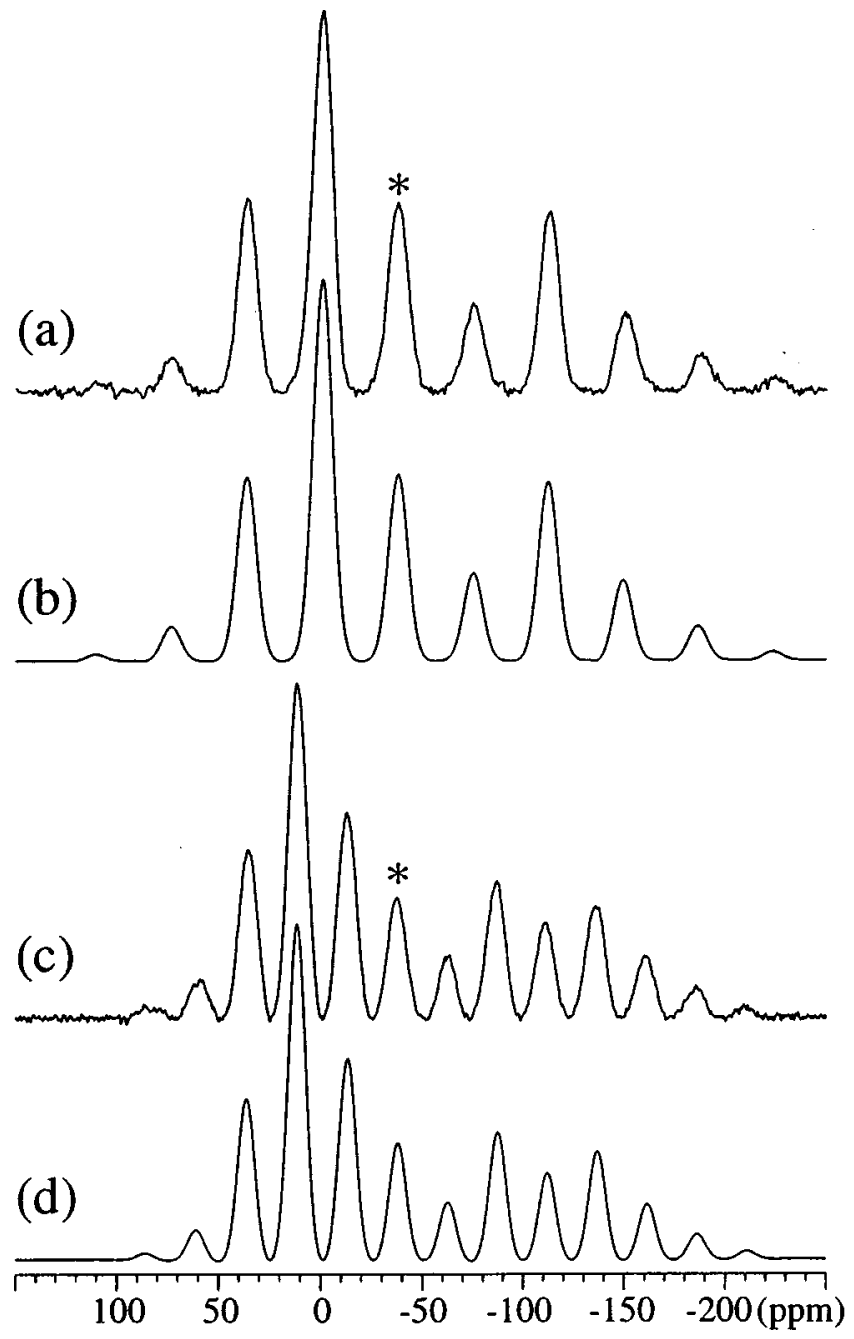

FIG. 2. Experimental (a) and (c) and simulated (b) and (d) ${ }^{31} \mathrm{P}$ MAS NMR spectra $(9.4 \mathrm{~T})$ of glass No. 2 (1.8\% $\mathrm{P}$ conc.) obtained using spinning speeds of $v_{r}=6000 \mathrm{~Hz}(\mathrm{a}),(\mathrm{b})$ and $v_{r}=4000 \mathrm{~Hz}(\mathrm{c}),(\mathrm{d})$. The experimental spectra were recorded using a relaxation delay of $600 \mathrm{~s}, 90$ scans (a) and 128 scans (c). The asterisks indicate the resonances corresponding to the isotropic chemical shift. The optimized simulations in (b) and (d) employ the ${ }^{31} \mathrm{P}$ CSA parameters listed in Table I.

Using Eq. (1) these data transform into $\delta_{\text {iso }}=-39 \mathrm{ppm}, \delta_{\sigma}$ $=+151 \mathrm{ppm}$, and $\eta_{\sigma}=0.0$, which indicate that the structural environment of the phosphorus atom proposed for the phosphorus-doped thin silica films in this work (Fig. 3) is also found in the silica glass preforms.

TABLE I. ${ }^{31} \mathrm{P}$ Isotropic $\left(\delta_{\text {iso }}\right)$ and anisotropic $\left(\delta_{\sigma}\right.$ and $\left.\eta_{\sigma}\right)$ chemical shift parameters for phosphorus deposited on a pure silicon wafer obtained from ${ }^{31}$ P MAS NMR experiments at different Larmor frequencies $\left(\nu_{L}\right)$ and spinning speeds $\left(\nu_{r}\right)$.

\begin{tabular}{cccccc}
\hline \hline P conc. $(\%)$ & $\nu_{L}(\mathrm{MHz})$ & $v_{r}(\mathrm{~Hz})$ & $\delta_{\text {iso }}{ }^{\mathrm{a}}(\mathrm{ppm})$ & $\delta_{\sigma}{ }^{\mathrm{b}}(\mathrm{ppm})$ & $\eta_{\sigma}{ }^{\mathrm{b}}$ \\
\hline $3.5 \pm 0.5$ & 121.4 & 6845 & $-38.4 \pm 1.0$ & $147 \pm 3$ & $0.00+0.26$ \\
$3.5 \pm 0.5$ & 121.4 & 3760 & $-38.9 \pm 1.0$ & $147 \pm 3$ & $0.13 \pm 0.11$ \\
$1.8 \pm 0.3$ & 161.9 & 6000 & $-38.0 \pm 1.0$ & $149 \pm 2$ & $0.25 \pm 0.20$ \\
$1.8 \pm 0.3$ & 161.9 & 4000 & $-37.9 \pm 1.0$ & $150 \pm 2$ & $0.08 \pm 0.06$ \\
\hline \hline
\end{tabular}

${ }^{a}$ Isotropic chemical shifts relative to an external sample of $85 \% \mathrm{H}_{3} \mathrm{PO}_{4}$.

${ }^{\mathrm{b}}$ The definitiion of the anisotropic shift parameters is given in Eq. (1). 
<smiles>C[Si](C)(C)OP(=O)(O[Si](C)(C)C)O[Si](O[SiH3])(O[SiH3])O[SiH3]</smiles>

FIG. 3. Proposed molecular structure of the phosphorus-doped environment in the thin silica films prepared in this work.

${ }^{29} \mathrm{Si}$ MAS NMR investigations were conducted to possibly gain further insight into the structure for the silicon part of the phosphorus-doped thin silica film. A ${ }^{29} \mathrm{Si}$ MAS NMR spectrum obtained under optimized experimental conditions is shown in Fig. 4. Two narrow resonances and their associated first-order low-frequency spinning sidebands are observed in addition to a very broad, low-intensity resonance appearing in the range -107 to $-122 \mathrm{ppm}$, inbetween the two spinning sidebands. The resonance at $-48.8 \mathrm{ppm}$ arises

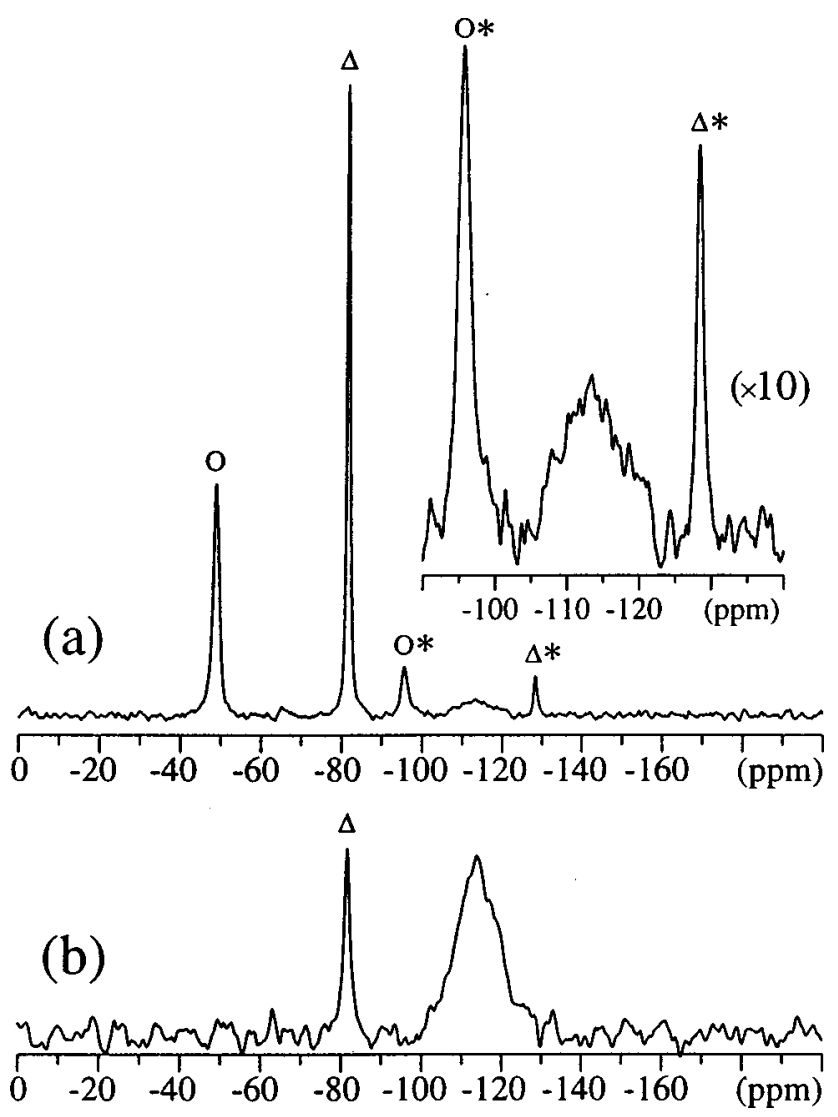

FIG. 4. ${ }^{29} \mathrm{Si}$ MAS NMR spectra $\left(9.4 \mathrm{~T}, v_{r}=3700 \mathrm{~Hz}\right)$ of (a) glass No. 1 $(3.5 \% \mathrm{P})$ in a $7 \mathrm{~mm} \mathrm{Si}_{3} \mathrm{~N}_{4}$ rotor with a sample volume of $340 \mu \mathrm{l}$ and (b) glass No. $2\left(1.8 \% \mathrm{P}\right.$, in a $7 \mathrm{~mm} \mathrm{ZrO}_{2}$ rotor, sample volume of $\left.225 \mu \mathrm{l}\right)$ obtained with a relaxation delay of $180 \mathrm{~s}$ and 371 scans and 1024 scans, respectively. The vertical expansion by a factor of 10 of the inset in part (a) corresponds to the vertical scale used for the spectrum in part (b). The circle indicates the resonance from the $\mathrm{Si}_{3} \mathrm{~N}_{4}$ rotor material while the triangle shows the resonance from nonetched silicon of the wafer. Peaks marked by asterisks are the corresponding spinning sidebands. Clearly the etching process has been much more efficient for wafer No. 2 . as a background signal from the $\mathrm{Si}_{3} \mathrm{~N}_{4}$ rotor, while the -81.6 ppm resonance is caused by residual pure silicon of the silicon wafer not being removed in the etching process. The observed isotropic chemical shift of $-81.6 \mathrm{ppm}$ is in good agreement with the value $\delta_{\text {iso }}=-80 \mathrm{ppm}$ reported for crystalline silicon. ${ }^{16}$ In that work ${ }^{16}$ crystalline silicon was obtained by annealing an amorphous silicon sample at $640{ }^{\circ} \mathrm{C}$. The similarity in chemical shifts indicates that annealing at $1100{ }^{\circ} \mathrm{C}$ does not change the local ordering of the crystalline silicon wafers used in this work. The broad resonance with a maximum at $-113 \mathrm{ppm}$ is assigned to a chemical shift dispersion of the different $\mathrm{Si}(-\mathrm{O}-)_{4}$ structures, including $(-\mathrm{O}-\mathrm{Si}-\mathrm{O}-)_{3} \mathrm{P}=\mathrm{O}$, of the silica glass. Although this resonance appears shifted somewhat to lower frequency, as compared to the ${ }^{29} \mathrm{Si}$ resonances for other silica samples, the broad resonance provides no additional clear-cut information regarding the structure of the phosphorus species in the silica film. However, using an appropriately constructed ${ }^{29} \mathrm{Si}-{ }^{31} \mathrm{P}$ double resonance MAS probe (not yet available in our laboratory), this resonance may turn out to be useful in a series of double resonance experiments, including $\left.{ }^{29} \mathrm{Si}^{3}{ }^{31} \mathrm{P}\right\} \mathrm{CP}$, which would serve to confirm the proposed structure in Fig. 3.

\section{CONCLUSIONS}

The recording of ${ }^{31} \mathrm{P}$ MAS NMR spectra for phosphorusdoped $(1.8 \%$ and $3.5 \%)$ thin silica films $(34 \mu \mathrm{m})$, deposited using PECVD techniques on a silicon wafer, has been achieved. Analysis of the spectra shows that only one single phosphorus chemical structure is consistent with the features of the spinning sidebands in these spectra. The molecular structure of this phosphorus-doped silica is proposed based on the ${ }^{31} \mathrm{P}$ CSA parameters determined from the ${ }^{31} \mathrm{P}$ spectral analysis and on the ${ }^{29} \mathrm{Si}$ MAS NMR spectra.

\section{ACKNOWLEDGMENTS}

The use of the facilities at the Instrument Centre for Solid-State NMR Spectroscopy, University of Aarhus, sponsored by the Danish Natural Science Research Council, the Danish Technical Science Research Council, Teknologistyrelsen, Carlsbergfondet, and Direktør Ib Henriksens Fond, is acknowledged.

${ }^{1}$ B. E. Warren, J. Am. Ceram. Soc. 17, 249 (1934).

${ }^{2}$ R. L. Mozzi and B. E. Warren, J. Appl. Crystallogr. 2, 164 (1969).

${ }^{3}$ S. Sen, J. Non-Cryst. Solids 261, 226 (2000).

${ }^{4}$ J. Nishii, K. Kintaka, H. Hosono, H. Kawazoe, M. Kato, and K. Muta, Phys. Rev. B 60, 7166 (1999).

${ }^{5}$ M. Fujimaki, T. Watanabe, T. Kasahara, N. Miyazaki, Y. Ohki, and H. Nishikawa, Phys. Rev. B 57, 3920 (1998).

${ }^{6}$ L. Skuja, J. Non-Cryst. Solids 239, 16 (1998).

${ }^{7}$ M. J. F. Digonnet, Rare Earth Fiber Lasers and Amplifiers (Marcel Dekker, New York, 1993).

${ }^{8}$ R. Kashyap, Fiber Bragg Gratings (Academic, San Diego, 1999).

${ }^{9}$ H. Eckert, Prog. Nucl. Magn. Reson. Spectrosc. 24, 159 (1992).

${ }^{10} \mathrm{R}$. Dupree, in Nuclear Magnetic Resonance in Modern Technology, edited by G. E. Maciel, NATO ASI Series C on Mathematical and Physical Sciences, Vol. 447 (Kluwer Academic, Dordercht, 1994), p. 339.

${ }^{11}$ D. C. Douglass, T. M. Duncan, K. L. Walker, and R. Csencsits, J. Appl. Phys. 58, 197 (1985).

${ }^{12}$ M. A. Hubbard, E. M. Gill, S. L.Gilbert, J. Xiong, H. Lock, G. E. Maciel, T. Taunay, and M. A. Putnam, OSA Conference on Bragg Gratings, Pho- 
tosensitivity and Poling in Glass Waveguides, Florida, 1999, p. 124

${ }^{13}$ D. A. Zauner, Master thesis, Mikroelektronik Centeret, DTU, 1996.

${ }^{14}$ H. J. Jakobsen, P. Daugaard, and V. Langer, J. Magn. Reson. 76, 162 (1988); U. S. Patent 4,739,270 (Apr. 1988)
${ }^{15}$ J. Skibsted, N. C. Nielsen, H. Bildsøe, and H. J. Jakobsen, J. Magn. Reson. 95, 88 (1991).

${ }^{16}$ W.-L. Shao, J. Shinar, S. Mitra, B. C. Gerstein, F. Li, J. Fortner, and J. S. Lannin, J. Non-Cryst. Solids 114, 232 (1989). 